\title{
Knowing and decorating the world Illustrations and textual descriptions in the maps of the fourth edition of the Mercator-Hondius Atlas (1613)
}

\section{T} his article analyses the Mercator-Hondius Atlas maps in the context of constructing knowledge of the world. In what follows, we analyse the elements of continental geographies and ocean spaces on the maps presented in the atlas. We take as our starting point the tension between empirical and theoretical knowledge and examine the changes occurring in the ways of representing land and sea on atlas maps which are evident in the Mercator-Hondius Atlas. Consequently, we investigate how the world was represented through information in pictorial and textual form. We argue that the maps in the Mercator-Hondius Atlas make explicit not only the multiple cartographical traditions and the layered nature of atlases as artefacts. They also exemplify the various coexisting functions of the atlas.

\section{Introduction}

This article analyses the fourth edition of the Mercator-Hondius Atlas which was published in Amsterdam in 1613. The particular edition analysed is currently in the possession of the Donner Institute, located in Turku, Finland. The atlas as a whole is the result of the efforts and endeavours of multiple different individuals including cartographers, engravers, and compilers. This edition consists of maps and texts prepared mainly by two notable cartographers of the sixteenth and seventeenth centuries, Gerard Mercator (1512-94) and Jodocus Hondius (1563$1612)$. Hence the atlas is referred to as the MercatorHondius Atlas (MHA).

The article examines how the world is constructed as a cartographical space by the illustrations and texts used on the atlas maps. In what follows, we analyse how the geographies of the lands and the seas are depicted on the maps authored by Mercator and Hondius. We investigate the illustrations and textual descriptions Mercator and Hondius used to represent the world and its regions. These two men each applied very different principles when preparing maps: Mercator considered himself to be a scholar aiming to produce the most accurate maps and emphasizing their informative content. Hondius, however, evolved from an engraver to a publisher of atlases and globes, turning them into a profitable business (van der Krogt 1997: 35; Zuber 2011: 516). We argue that the maps in the Mercator-Hondius Atlas can be read as a demonstration of the layered nature of the atlas as an epistemological artefact.

The principles and practices employed by different early modern cartographers in constructing their maps and atlases is a widely researched topic. Mercator, particularly famous for the projection bearing his name, has been examined as an individual who greatly transformed the principles of mapmaking and was highly influential on his contemporaries (e.g., Brotton 2012: 218-59; Holzer et al. 2015). Hondius, by contrast, has received less attention as an individual, although his importance, practices and preferences as a cartographer have been examined (e.g., Koeman 1965; Sutton 2009: 2012). The Mercator-Hondius Atlas, alongside others, has been studied extensively from a carto-bibliographical point of view. These studies have aimed at identifying the different editions of the atlases, investigating their particularities and examining their production processes (e.g. van den Broecke 2009; van der Krogt 1996, 1997, 2005). Furthermore, many scholars have aimed at identifying the practices and places of atlas production and transforming them into profitable businesses in sixteenth- and seventeenth-century 
Europe (van den Broecke 2009, Koeman et al. 2009, van der Krogt 2015). Attention has also been directed at identifying the differences in style, methods and motivation amongst cartographers and the changes that occurred in this area (e.g. van den Broecke 2015). For example Elizabeth Sutton (2009, 2012) has researched the map-making business by examining how ethnographical illustrations came to be used on maps by different cartographers in early modern Holland. The direct study of map signs and illustrations on maps has, however, been the focus of only a few (e.g. George 1969; van Duzer 2012, 2013).

As an organized, systematic collection of maps, an atlas in the modern sense of the word was compiled for the first time by Abraham Ortelius in 1570. Contrary to the maps compiled and bound together previously at the request of collectors, late sixteenthcentury atlases consisted of printed maps of uniform size accompanied by an on verso text (Koeman et al. 2007: 1318; della Dora 2009: 245-6; van den Broecke 2009: 16; van der Krogt 2015: 112-13). Ortelius, whose atlas was published in approximately 40 different editions between 1570 and 1612 (van den Broecke 2009: 27-30; see also Suarez 1999: 164) instructed the readers of his atlas to think of it as a journey. Based on contemporaneous knowledge of the world rather than classical sources, the beautifully engraved maps were to be looked at as parts of the journey with the descriptive on verso texts offering the armchair travellers a place to rest before travelling on (Ortelius 1606, quoted in della Dora 2009: 247; see also Suarez 1999: 164). Ortelius' atlas was designed to appeal to different readers. Ortelius prepared different editions of the on verso texts for people interested in the scholarly aspects of geography, or for non-academic readers fond of miracles and wonders and beautiful and magnificently decorated books (Tooley 1949: 30; Suarez 1999: 164; van den Broecke 2009: 30-2, 269). ${ }^{1}$

The second atlas, which achieved comparable commercial success, was the Mercator-Hondius Atlas, first published in 1606 (Koeman et al. 2007: 1325). The maps prepared by Mercator had been previously published in 1595 by Mercator's son as a collection. These maps had been published before

1 Ortelius prepared two different types of on verso texts for the Latin, Spanish, Italian and English editions on the one hand and Dutch, French and early German editions on the other (van den Broecke 2009: 30-2, 269). as regional collections by Mercator himself in 1585 and 1589 (van den Broecke 2009: 240; van der Krogt 2015: 114). ${ }^{2}$ The atlas published in 1595 included these maps, accompanied by maps of the world and the continents, a cosmographical meditation, and on verso texts describing the nature, history and governance of the area in question. Mercator's grandsons engraved the maps of the continents using Mercator's 1569 map of the world as their model. It was published only a year after Mercator's death, with limited success. (Keuning 1947: 38, 43; Koeman et al. 2007: 1323; van den Broecke 2009: 240)

Consequently, Mercator's grandson sold the plates of his father's atlas privately to the Dutch publisher Cornelis Claesz. and engraver Jodocus Hondius in 1604 (van der Krogt 1997: 34; Meurer 1998: 63-5; see also Koeman et al. 2007: 1324). Claesz. and Hondius worked together and published an expanded, revised edition of the atlas in 1606 with 36 new maps and added new Latin text. This atlas has subsequently been named the Mercator-Hondius Atlas. The second edition was followed by new editions almost yearly and after Claesz's death in 1609, Hondius became the sole owner of the plates. The 1613 edition, which is the focus of this article, is a reprint of the edition quarta, first published in 1611. It was published after Hondius' death (1612), evidently by Hondius' widow and sons, who continued publishing atlases. ${ }^{3}$

2 Before the publication of the atlas, Mercator himself had published works such as Tabulae geographicae Cl. Ptolemei (1578) and other tabulae geographiae collections published in 1585 and 1589 , which consisted of maps of locations all over Europe. Mercator published sheets of the maps of Gallia, Germany and the neighbouring areas of Belgium in 1585 . The sheets containing the maps of the regions of Italy, Greece and the Balkans were published in 1589. The maps published in collections between 1585 and 1589 with the 29 unpublished maps formed the content of the original Mercator atlas, Atlas sive cosmographicae meditationes de fabrica mundi et fabricati figura (1595). See Mercator 1585a, 1585b, 1585c.

3 Hondius' younger son, Henricus Hondius took over the production of Mercator-Hondius atlases around 1620. He was the first to carry out dramatic changes in the atlases by putting his own name on several of Mercator's maps in 1628 edition of atlas. After 1630 the amount of maps in the atlases increased as new editions were printed. This period saw the opening of a much more complicated chapter in the history of this atlas. Hondius' son Henricus Hondius and his brother-in-law Johannes Janssonius published several 
(Van der Krogt 1997: 34; Koeman et al. 2007: 1325; Sutton 2012: 173-4; van der Krogt 2015: 120)

The fourth edition of the atlas consists of 150 maps authored mainly by Mercator. Only a portion of the maps added by Hondius were authored by him (Keuning 1947: 45-6). ${ }^{4}$ The atlas includes maps depicting Europe, Africa, Asia, and America and various regions of Europe and the northern polar region, authored by Mercator. Hondius authored maps of Europe, Asia, Africa and America. Maps of Europe and its regions dominate: 122 maps out of the total of 150 depict Europe or regions of the same. Except for Spain the maps of the European regions were prepared by Mercator. In the 1613 atlas, therefore, the works of different individuals were brought together to form one artefact that was no longer uniform in style (Keuning 1947: 45). Copiers and engravers - such as Mercator's son Rumold Mercator (1545-99) and grandsons, Hondius' brother-in-law Pieter van Keere (1571 - c. after 1646), and Baptista van Doecetum (d. 1611) - were involved in the process of producing the maps bound in the atlas. In addition, the atlas included maps which were originally copied from other authors such as Aegidius Martini, ${ }^{5}$ François de La Guillotière (d. 1594), Eilhard Lubinus (15651621) and Zacharias Heijns (1566-1630). (Wallis 1984: 149; Schmidt-Biggemann 1987; Koeman et al. 2007; Pelletier 2009; RKD Netherlands Institute for Art History 2015)

In the following sections we take as our focus the representational choices made by the authors. We seek to understand the informational content of the maps: the different representational choices made in order to communicate knowledge, theories and speculations about the world. Knowledge of the world was simultaneously constructed in the atlas through the maps and the on verso texts. However, in our analysis we limit ourselves only to the maps

editions of the same atlas concurrently with Blaeu, with minor differences, between the years 1630-41. See Keuning 1947; van der Krogt 1997: 35-7 and 2005: 31-2; Koeman et al. 2007: 1325-1330.

4 The numbers of maps in the atlases increased as new editions were printed: the tenth edition contained 164 maps. See Keuning 1947; Koeman et al. 2007: 1325.

5 There is only a little known about the Dutch expert in law and mathematics Aegidius Martini. Since the map of Lumburgi included in the atlas is said to have been produced by him in 1603 , it is logical to assume he was born in the sixteenth century and died in the seventeenth century. See e.g. van den Broecke 1996. and examine the character of the information transmitted in them. As a mode of communication maps, compared to texts, provided the user of the atlas with a simplified view of the world. What was represented in the maps, therefore, made manifest the conclusions drawn by the cartographers on the basis of the variety of sources they had perused when constructing their maps. By compiling accounts of travellers with descriptions of geographers, theories from classical authorities, and representations on older maps, Mercator and Hondius, like other cartographers of their time, created their own cartographical synthesis and decided what was to be included. (Karrow 2007: 4; Cosgrove 2007: 102; Schilder 1984: 493)

Our analysis focuses, therefore, on what kinds of textual descriptions and illustrations Mercator and Hondius used in their maps. The conclusions we draw are not definitive, as it is impossible to know the intended function or the actual reading of a particular text or illustration. However, taking note of these different layers of knowledge sheds light on the practices of formulating cartographical images of the world and its regions. Consequently, we analyse the epistemological basis of and the differences between the illustrations and textual descriptions employed by Mercator and Hondius.

\section{Continental geographies}

Starting from the Renaissance, a slow shift from a speculative global geography to an empirical one began (Cosgrove 2007: 102; della Dora 2009: 245). Simply put, 'the relationship of the map to its sources in the observed world' changed fundamentally (Woodward 2007: 12, 17-20). As the production of maps increased tremendously and the use of coordinates became widely adopted, general understandings of the world changed. The graticule became the symbol of, and means for, gathering knowledge of the world to form a somewhat coherent picture (ibid. 23).

During the sixteenth and seventeenth centuries explorations of the world produced knowledge of coastlines, so that not only the interiors of Africa, Asia and the America, but also the high seas, continued to be relatively unknown to the Europeans. Regarding the interiors of the continents and the open sea the lack of abundant empirical information was therefore compensated for with information deriving from indigenous informants, analogies and hypotheses (Crone 1978: 76). Early modern cartographers con- 
tinued the cosmographical mode of filling the blank spaces on sea and land with, for example, descriptions and illustrations of nature, ethnography and history (Cosgrove 2007: 102). Cartographers, therefore, participated in a particular way in communicating and transmitting ideas about exotic animals, plants and ethnographical materials from 'foreign lands'. These were often displayed in cabinets of curiosity and communicated to wider audiences through texts and illustrations (Daston and Park 1998: 173, 180-1).

The choices made in the late sixteenth- and early seventeenth-century atlases provide reflections of the ways the world was comprehended and the different principles according to which it was divided into regions. As a result of crossing the Atlantic and the discovery of the fourth continent at the end of the fifteenth century, European global geography, and the means of representing it on maps, needed to be reconfigured. During the Renaissance the threefold continental system deriving from ancient Greece had been revived and affirmed by scientific observations. However, as the sphere of European action expanded to a new land mass, the geographical schematization of the world started to be re-established as the Americas were 'invented'. The process was gradual and the way in which the Americas came to be acknowledged as part of the human world - as opposed to considering them as an Orbis Alterius relied heavily on anthropological data (Lewis and Wigen 1997: 23-6). ${ }^{6}$

The forms of geographical knowledge communicated through the atlas maps ranged from eyewitness information, hypotheses, and descriptions by the classical authorities to hearsay. Map signs - such as houses as the signifiers of towns, trees as signs for forests, and so on - were used on almost every map. However, depending on the cartographer, the appearance of the signs varied, as no standard forms existed. In addition to these signs - which were also used to communicate information about the characteristics of the land - its topography and capacities - the environment was described in words (DelanoSmith 2007: 535-6). ${ }^{7}$ Mercator aimed at producing a uniform system of signs for his maps as he aimed at a consistent style. For Hondius, however, uniform-

6 On the development of Renaissance map projections, see Snyder 2007.

7 On the plurality of map signs in Renaissance topographical maps, see Delano-Smith 2007. ity was not such an important aim: he did not alter the Mercator plates or change his own style when engraving maps, but simply combined these different styles of maps in the atlas.

Generally, the textual descriptions used in the maps informed the viewer about the discoverers, as well as the known characteristics of, and the assumptions concerning, the particular region. For example, on Mercator's map of the New World, the role of Christopher Columbus as its discoverer is explained. Furthermore, the nature of the environment - a deserted wasteland - on the northern coast is described as containing numerous wild horses. ${ }^{8}$ Similar 'eyewitness' descriptions can be found in a number of regions outside Europe. Consequently, the viewers of the atlas gained information about, for example, the sea currents in the North Pole region, the island of Java as the source for spices, and about the inhabitants of various regions. The North Pole region as rendered by Mercator, and the inlands of South America and Africa by Hondius are of special interest here, as they contain ethnographical descriptions of the tall 'Patagonians', the four-foot tall 'Pygmies', the 'native' places, and the 'cannibals.'

Alongside ethnographical descriptions, the maps also contain some ethnographical imagery. Although it could be stated that they are not abundant in the atlas maps in total, multiple illustrations are found on the maps depicting regions outside of Europe. However, there are clear differences between the authors, which highlights their differing ideals and preferences in map-making. Mercator does not present ethnographical knowledge in pictorial form on land, except on one occasion, when he depicts zolotaya baba - an old woman with two children in her arms sitting on a pedestal - a figure worshipped by local indigenous people in eastern Siberia. The land areas are empty of all the other ethnographical images when it comes to maps prepared by Mercator - all other imagery is found on the maps prepared by Hondius. However, even the imagery Hondius uses is not in a dominant position on the maps. Indeed, only after the 1620 do the illustrations on these maps become really abundant (Sutton 2012: 166).

Hondius uses ethnographical images in seven maps in all. The maps of the Americas by Hondius,

8 Mercator: America sive India Nova, MHA 1613.

9 Hondius: America Meridionalis; Hondius: Nova Africae Tabula; Mercator: Septentrionalium terrarum description; Mercator: Africa; MHA 1613. 

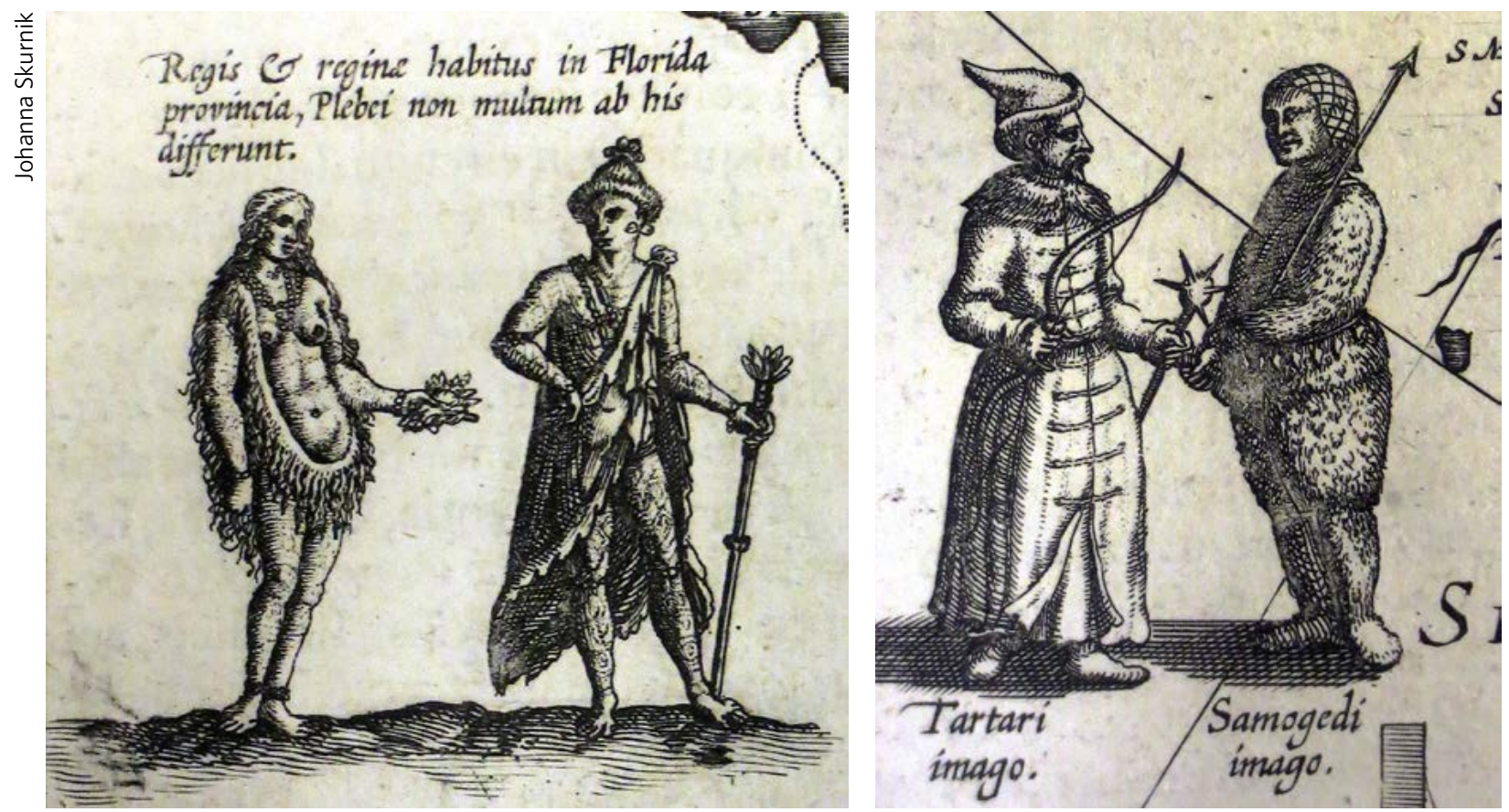

Details from maps of Virginae item et Florida and Tartaria by Hondius.

or some of them, are the ones with the most imagery in the atlas. In the map depicting both North and South America and a portion of Terra Australis, 'Brazilians' eating and drinking are portrayed in a separate image in the bottom left corner. On the map of the eastern coast of North America and the map of South America, 'native' people are pictured. In addition, 'natives' are depicted sailing in their boats along the eastern coasts of South America and North America. ${ }^{10}$ Similarly on the maps of Tartary and China, images of a Tartar, a Samoyed and a campsite have been inserted. ${ }^{11}$ Sutton $(2009,2012: 184,161-$ 92) has demonstrated that Claesz. and Hondius established this type of imagery, along with the decorative borders, in the 1600 s. However, they became really popular only some decades later, in the 1620 .

In general, the illustrations on the maps communicated ethnographical information to the European audience, as well as assumptions concerning, and stereotypes of, peoples in other parts of the world. By contrast, in the maps of Europe, or parts of it, the

10 Hondius: America Septentrio; Hondius: Virginae item et Floridae, America Provinciarum, nova descriptio; MHA 1613.

11 Hondius: China; Hondius: Tartaria; Hondius: Virginae item et Floridae, America Provinciarum, nova descriptio; Hondius: America Meridionalis; MHA 1613. difference is clear; no imagery is used there. Instead, central Europe especially is filled with natural features, place-names, and political boundaries. This is due to differences in the ways these areas were known and understood. Compared to the other continents Europe was culturally familiar and relatively well known. Even though the locations of many places hadn't been determined accurately, they were still known to exist. ${ }^{12}$

The ways in which various ethnic groups were represented by European cartographers, then, reveal the processes of defining not only that which is nonEuropean, but also that which is European. In artwork, published travel accounts, illustrations and maps - as, for example, Bernard Smith (1992: 10) argues - the encounters with non-Europeans became exoticised, endowing them with ideological meanings. ${ }^{13}$ Atlases were also an influential medium within these processes. In the Mercator-Hondius Atlas the idea of the exotic as an ethnographical personifica-

12 Europe can be seen as a counterpart to the 'peripheries' which were - in addition to the Americas, Africa, Asia and the southern continent - found as nearby as Scandinavia and present-day Eastern Europe. On the land surveying methods employed in early modern Europe see Lindgren 2007.

13 On the use of the mode of the exotic, see Smith 1992: 11-39. 
tion is, indeed, most explicit on the title page. It is here that the King of Mauretania is depicted studying the globe, surrounded by allegorical images of the six regions of the world. Alongside Africa, Asia and Europe stand 'Peruana', 'Mexicana' and 'Magalanica', representing America. The figures were added to the title page by Hondius for his first edition of the atlas, thus transforming the frontispiece by Mercator into an illustration very similar to that used by Ortelius in his Theatrum (van der Krogt 2005: 32). ${ }^{14}$

Elizabeth Sutton (2012: 163) argues that the symbolic personifications of the continents used in the frontispieces were a means of representing the essential characteristics associated with the continent portrayed. The images simultaneously legitimated the new geographical information presented and decontextualised the figures, turning them into exotic stereotypes (Sutton 2012: 163, 166-7). In this dynamic process the allegorical imagery was not replaced with factual descriptions. Rather, as Sutton (2009: 19) puts it, they 'worked in tandem', embedding information about places with new meanings in a European context.

Practices concerning the representation of information about the environment in the atlas maps varied. In general, cartographers used analogies when processing the information about unknown or partly unknown environments. As Sutton (2012) has demonstrated in her study of early modern Dutch prints of Africa, the comparative method, which was applied when producing ethnographical and anthropological information about Africa, was an established mode of knowledge production in early modern Europe. On the continental maps, this is evident as mountain ranges and river networks occupy lands as yet unexplored. The basis of these assumptions lay in understandings of European geography and theories formulated during the classical period. In the maps, these theories were combined with information deriving from coastal surveys, which at times clashed.

14 The most important difference is that in the frontispiece by Hondius. Europe is placed amongst other figures standing at the top of the architectonic frame. In the frontispiece of Theatrum the Renaissance iconographic tradition inspired by the classical past was combined with a hierarchical representation of the continents. Sutton sees this as the result of artistic vision and balance. See Sutton 2012: 169, 174.
Consequently, the lack of information becomes explicit only on a few occasions as the coastlines are marked with dashes demonstrating ignorance of their actual shape. ${ }^{15}$ Contrasting these examples with the overall representations of the coastlines of other land masses makes evident interesting aspects of the cartographical methodologies in use. Principally what becomes explicit is the interplay of empirical and speculative information.

The polar regions provide prime examples of areas that were the result of combining speculation and items of empirical information. Mercator envisioned the North Pole to comprise of four different islands. This map had also been published as an inset on his 1569 map of the world. As Edwin Okhuizen (1994: 5-6) emphasizes, when the map was published in the 1595 atlas, it was the first atlas map to focus solely on the Arctic. For the atlas published in 1606 by Hondius, portions of it were modified to incorporate the newest information gained (ibid. 10). Detailed descriptions of the nature of the waterways, their lengths and seasonal changes are presented on this map. In addition, Mercator uses descriptions about the people living there; the Screlingers. These descriptions can, perhaps, be seen as Mercator's attempt to lend authority to his description of an area known only vaguely. ${ }^{16}$

Placing descriptions of the environment and its inhabitants on the map, therefore, demonstrates how Mercator combined his own visions with items of 'eyewitness' information. In the textual descriptions accompanying the map on verso, the sources used and the choices made are described in detail and Mercator explains how the knowledge of the geography of the polar region derives from the accounts of various English travellers and a Welsh chronicler, Giraldus Cambrensis (c.1146 - c.1223). As such, the map of the North Pole makes explicit many important details about the process of constructing maps. It highlights the nature of maps as examples of cartographical visions and ideals and subjective choices.

15 See the southern coast of Java in Hondius' Insuale Indiae Orientalis Pracipuae, In quibus Moluccae celeberrimo sunt, the southern coast of one of the islands forming the Arctic in Mercator's Septentrionalium terrarum descriptio and the south-eastern coast of Nova Zembla in Hondius's Tartaria, MHA 1613.

16 Mercator: Septentrionalium terrarum descriptio in Mercator and Hondius 1613. See also Okhuizen 1994. 


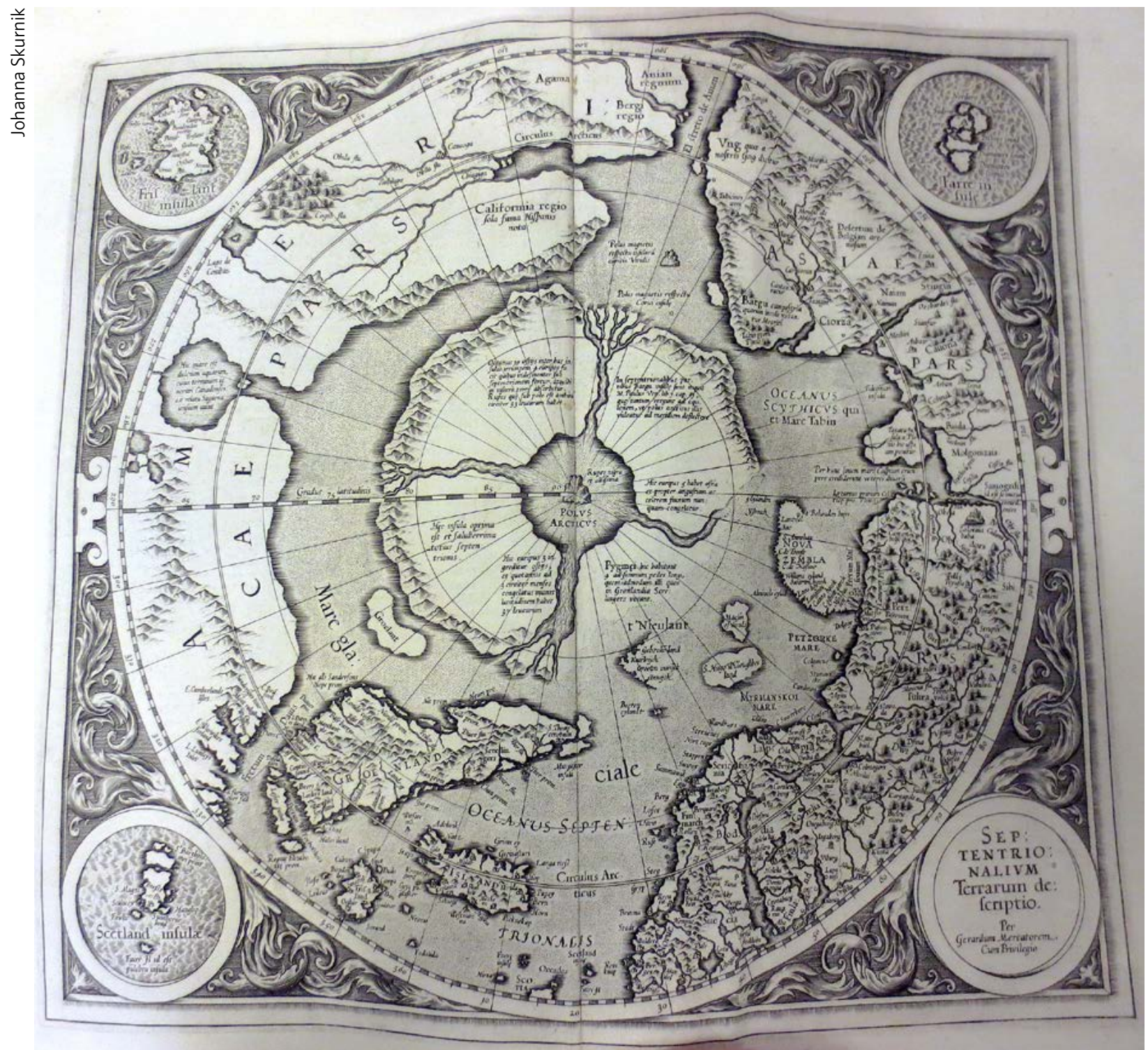

Map of the North Pole by Mercator.

The shape and size of Terra Australis Incognita was also an enduring item of speculation in early modern cartography. In the atlas portions of this region are depicted on eight different maps, four of them authored by Mercator and four by Hondius. ${ }^{17}$ Belief in the existence of the southern continent derived from two main sources. Firstly, theories of the ancient Greek philosophers argued for the existence of a southern land mass to balance the Earth. Secondly,

17 Hondius: America; Hondius: America Meridionalis; Exquisita \& magno aliquot mensium periculo lustrata et iam retecta Freti Magellanici facies; Hondius: Nova Africae Tabula; Mercator: Africa; Mercator: Asia; Mercator: America Siue India Nova; Mercator: Orbis Terrae Compendiosa Descriptio; MHA 1613. information deriving from travellers to Asia and Java such as Marco Polo (1254-1324) and Ludovico di Varthema (c.1470-1517) was used as the basis for depicting the coastlines of the southern continent (Gascoigne 2014: 25-6). Mike Zuber (2011: 533) emphasizes that specifically Mercator's depiction of the continent in his 1569 map of the world became the point of reference for many cartographers. Mercator's theory of the existence of the continent and the shape of its shoreline resulted mainly from his reading of travel accounts by explorers. His theory of the geography of the Terra Australis is explicitly expressed in the map of the world engraved by his son Rumold. ${ }^{18}$

18 Mercator: Orbis Terrae Compendiosa Descriptio, MHA 1613. 


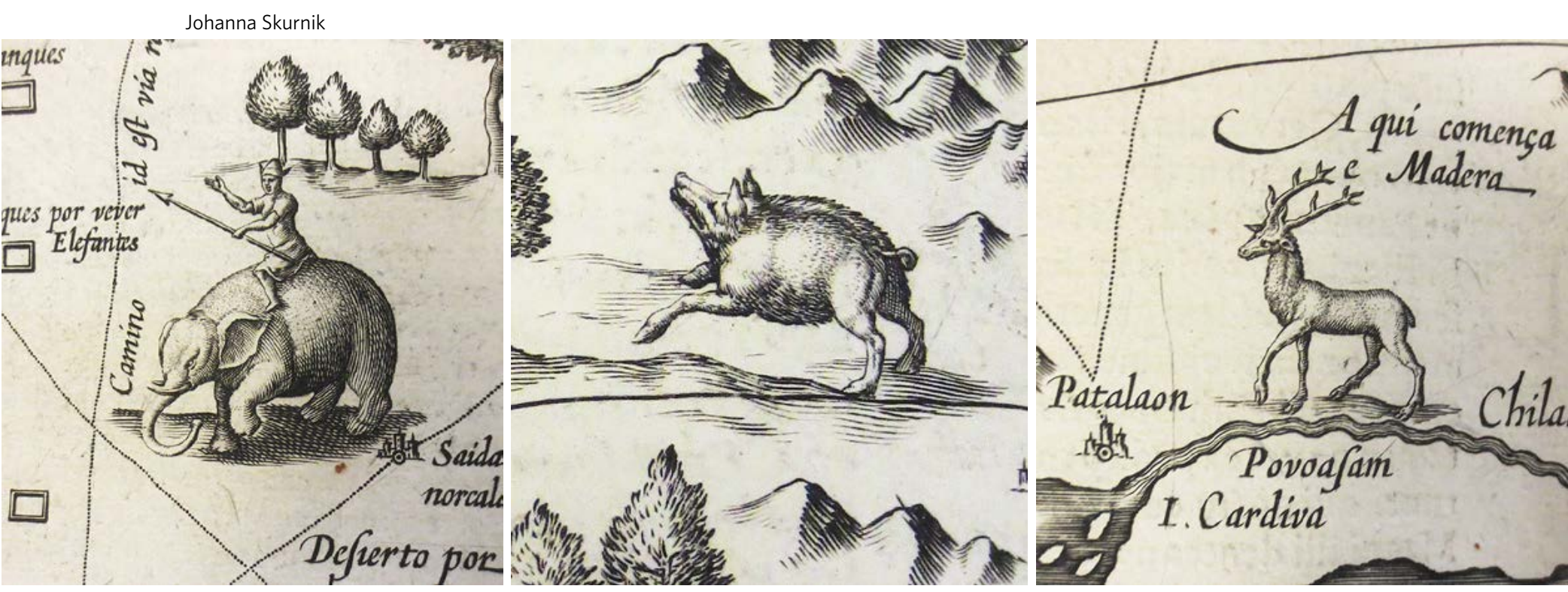

Details from maps of Nova Africae Tabula and Ins. Ceilan que Incolis Tenarifin dicitur by Hondius.

Indeed, many of the land discoveries made in the South Seas were usually understood to be portions of the southern land. Forming a cartographical image based on the information from travellers was, however, difficult. The descriptions lacked precision, a fact which challenged the map-makers' abilities to incorporate the new data into the 'pre-existing grand image of the world' that was being altered by the very same information at hand (Zuber 2011: 535, 538). The motivations of the choices made, of course, varied, arising sometimes from the need to make the maps more appealing to potential buyers, at others from a desire to illustrate, as in the case of Mercator, one's own geographical theories (ibid. 538-41). What the map-makers have chosen to depict on their maps and how, should, therefore, be examined in more detail as it is exemplary of the processes of knowledge production.

For example Tierra del Fuego was at first depicted as a part of the southern continent. This is explicit on many of the maps in the atlas. ${ }^{19}$ An interesting example is the last map of the atlas, depicting the Strait of Magellan. This map stands out as it is depicted with accurate information concerning the depths measured by the soundings. The map is oriented north, with South America at the bottom. Portions of the coastline are depicted with dashes,

19 For example, Hondius: America; Hondius: America Meridionalis; Exquisita \& magno aliquot mensium periculo lustrata et iam retecta Freti Magellanici facies; MHA 1613. contrasting with the accurately-known coasts along the strait. The map is illustrated with sea lions on the land and penguins decorating the cartouche. In addition, the map contains a separate panoramic illustration of the strait. ${ }^{20}$

The panorama of the strait especially makes explicit how the illustrations used in or alongside the maps should not be understood as mere decorations: they served a purpose of communicating and establishing information about the area in question. The panorama was exhibited as something the sailors had seen and described - it was something the author of the map, who in fact was neither Mercator nor Hondius, considered important enough to be incorporated into the map. ${ }^{21}$ Similarly, the animals occupying lands on Hondius' map of Africa and Ceylon, should not be passed by merely as things being used to fill the space. As Wilma George (1969: 21-5, 56-85) emphasizes, animals and plants were at times used 'diagnostically' to represent the lands. Indeed, the dromedary in the Saharan desert, the elephant near the River Niger and the wild boar in Ceylon can, perhaps, be seen as indicative images rather than as simply decorative ones. ${ }^{22}$

20 Exquisita \& magno aliquot mensium periculo lustrata et iam retecta Freti Magellanici facies, MHA 1613.

21 Peter van der Krogt has identified Zacharias Heijns as the author of the map. His name was erased from the map in later versions. See van der Krogt 1997.

22 Hondius: Nova Africae Tabula; Hondius: Ins. Ceilan que Incolis Tenarifin dicitur; MHA 1613. 


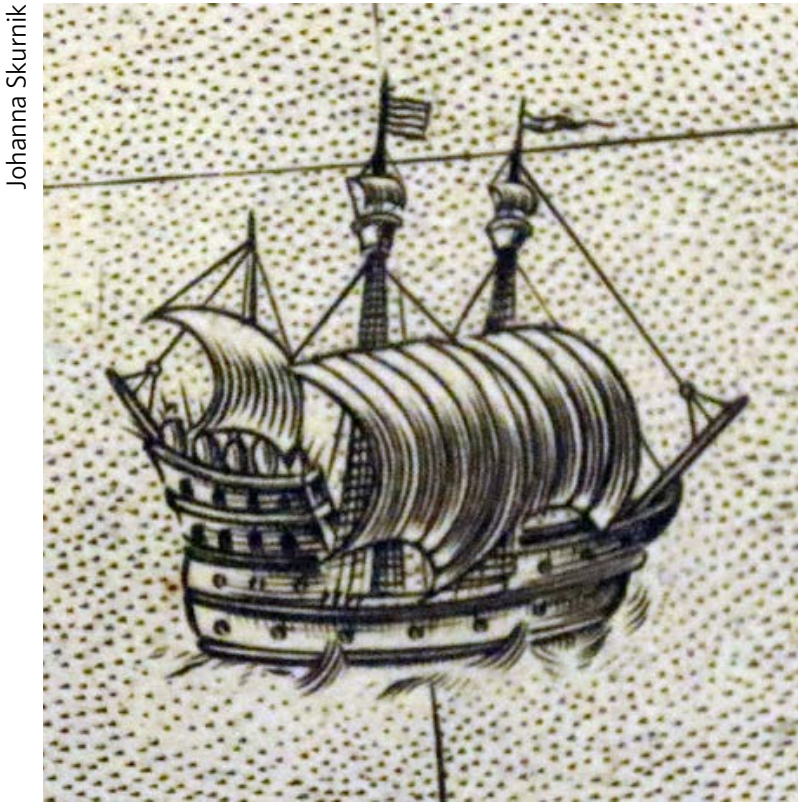

On the left, a ship depicted on the map of Anglia Regnum by Mercator. On the right, a ship from the map of China by Hondius.

Depicting the relatively unknown lands of the world either as empty spaces or, as was more common, as spaces filled with elements of physical geography, textual descriptions and images, makes explicit the epistemological practices of early modern cartographers. The different methods and the diversity of sources for making the continental spaces understandable and 'known' exemplify the layers of knowledge included on the atlas maps. Some descriptions constructed a cartographical image of the peculiarities encountered. Others made explicit information about the characteristics and resources of the area: for example, the abundance of spices in Java or gold deposits found in the Appalachian Mountains. ${ }^{23}$ The ways in which different areas were described depended on the sources available and the choices made by the cartographers. The maps transmitted different types of information about the world. Therefore, the atlas maps can be seen as reflections of the processes of knowledge production; of how the world was transformed into comprehensible spaces.

23 For example, Mercator: Orbis Terrae Compendiosa Descriptio; Hondius: Virginae item et Floridae, America Provinciarum, nova description; MHA 1613.

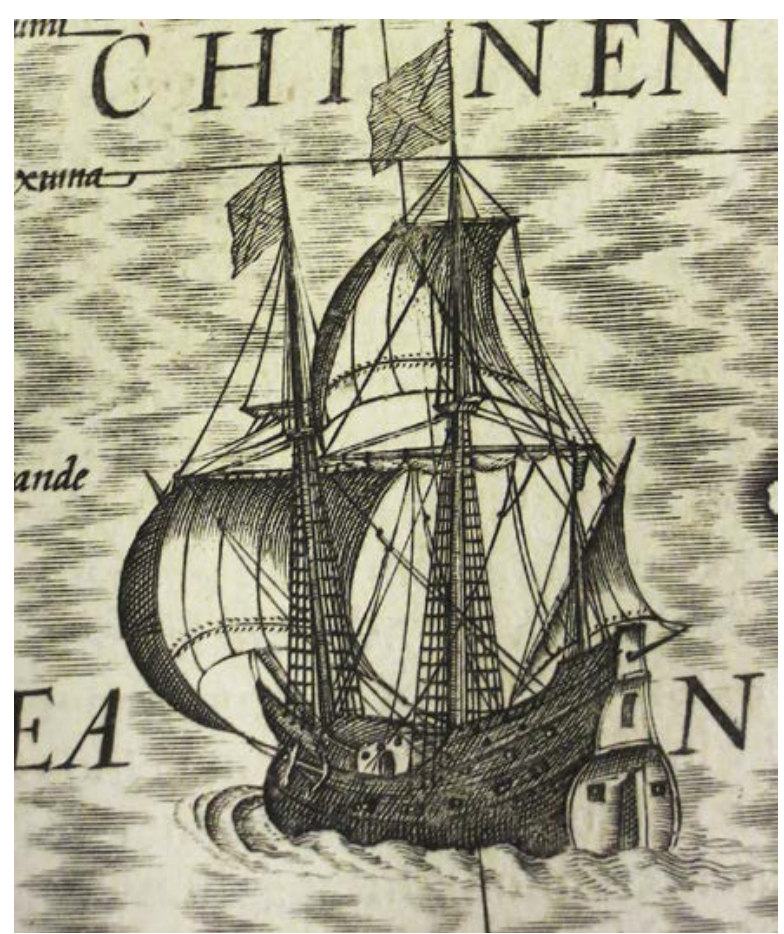

\section{Depicting the ocean spaces}

In the sixteenth century, there already existed a branch of mapping - maritime cartography - which produced piloting guides and nautical maps focusing exclusively on marine spaces, such as ones made by the Dutch cartographer Lucas Waghenaer (Schilder and van Egmond 2007: 1384). However, these charts did not solely represent marine spaces; there were invariably also terrain areas depicted on the borders of these maps. Similarly, terrain-oriented atlases, such as the atlas in question here, did not solely represent the continental regions, but also the marine spaces around it. This was simply the nature of the quadrangular-shaped maps in atlases. Therefore by scrutinizing the 1613 Mercator-Hondius Atlas the reader got an impression of both continental and marine geographies.

As the geographer Philip E. Steinberg (2001: 105) has stated, the shift in Western culture to a perception of the ocean spaces as a negligible place occurred at the turn of the sixteenth and the seventeenth centuries. As a consequence characterisations of the sea became more benign, but at the same time it lost much of its former significance. Earlier conventions which saw the ocean space as a terrifying wilderness were replaced little by little with the idea of it as rather being a void between continents.

The ocean space was a meaningless area in the maps of the atlas in the sense that both Mercator 

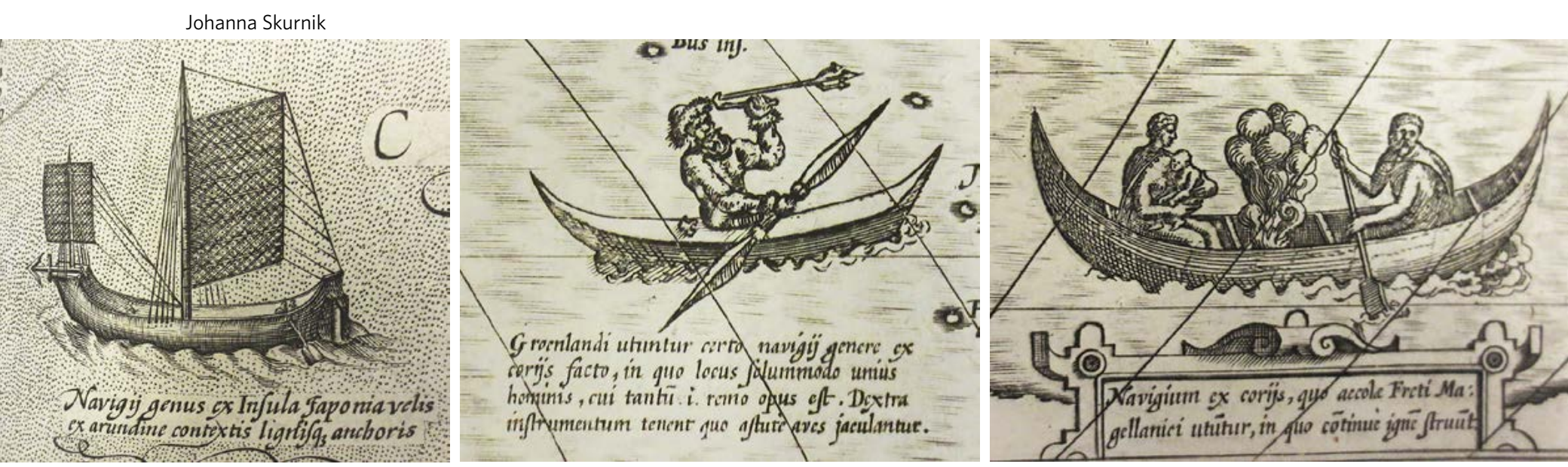

In these pictures from maps produced by Hondius there is a 'Japanese ship' and two different boats, in which there are 'natives' said to be living in Greenland and near the Strait of Magellan.

and Hondius placed textual descriptions concerning the knowledge of the continents that were being depicted on the map on the sea areas. Only with a few exceptions do these textual descriptions focus on the sea itself. An example of this is the map of the polar regions by Mercator, in which there is an account of the sea currents. ${ }^{24}$

However, the ocean spaces on the maps of the atlas did not only serve as a site for textual descriptions. As a matter of fact, they were simultaneously a place for various different representations and signs concerning the terrestrial space. There were various depictions of ships and boats, as well as sea monsters, both decorative ones and those representing the vitality of the life of the ocean, and creatures which clearly represented known marine animals. Consequently, the ocean space in the Mercator-Hondius Atlas was not represented merely as a meaningless void, but also a subject of knowledge.

The sea is visible in 105 of the in all 150 maps of the atlas. Of these maps, where there are sea areas, 86 were originally produced by Mercator and 38 added by Hondius. A little less than half of these maps included illustrations of sea monsters or ships. It is, however, noteworthy to mention that from Mercator's maps approximately one sixth included depictions of ships or monsters, whereas almost three quarters of maps added by Hondius included these illustrations.

Of all the representations on the ocean spaces of the atlas's maps, depictions of ships are presented most. As Richard W. Unger (2010: 149) has stated,

24 Mercator: Septentrionalium terrarum descriptio, MHA 1613. by the end of the sixteenth century, ships were found everywhere on the seas in Dutch maps, even in cartouches. In the Mercator-Hondius Atlas, there are small-sized ships as well as larger ones, found in altogether 42 maps of the 105 maps containing representations of ocean space, of which two thirds were on Hondius' maps and one third on maps by Mercator.

The various ships depicted on the maps of both Hondius and Mercator were usually decorative. However, they can be also interpreted as symbolising the ability of humans to brave the dangers of sea travel and encouraging people to make new voyages (Unger 2010: 1; van Duzer 2013: 118-19). One can also interpret ships as symbolising political control over the seas (van Duzer 2013: 119). For example, many ships are depicted bearing different flags on their masts as indications of the identity of their owners. ${ }^{25}$

On the maps made by Hondius some of the illustrations can be seen as representations of the typical vessels used in particular places. For example, there is 'a ship from the Island of Japan' added on to the Sea of China on a map of Iaponia. In addition, Hondius' map of America has two illustrations of small boats and one kayak, all with indigenous people in them. ${ }^{26}$

Consequently, this became part of the ethnographical convention of representation which, as Sutton (2012: 162) notes, was modified in Hondius'

25 See, e.g., R. Mercator: Orbis Terrae Compendiosa Descriptio; Hondius: Nova Europa; Mercator: Anglia regnum; Pieter van Keere: Campriae Typus; MHA 1613.

26 Hondius: Iaponia; Hondius: America; MHA 1613. 


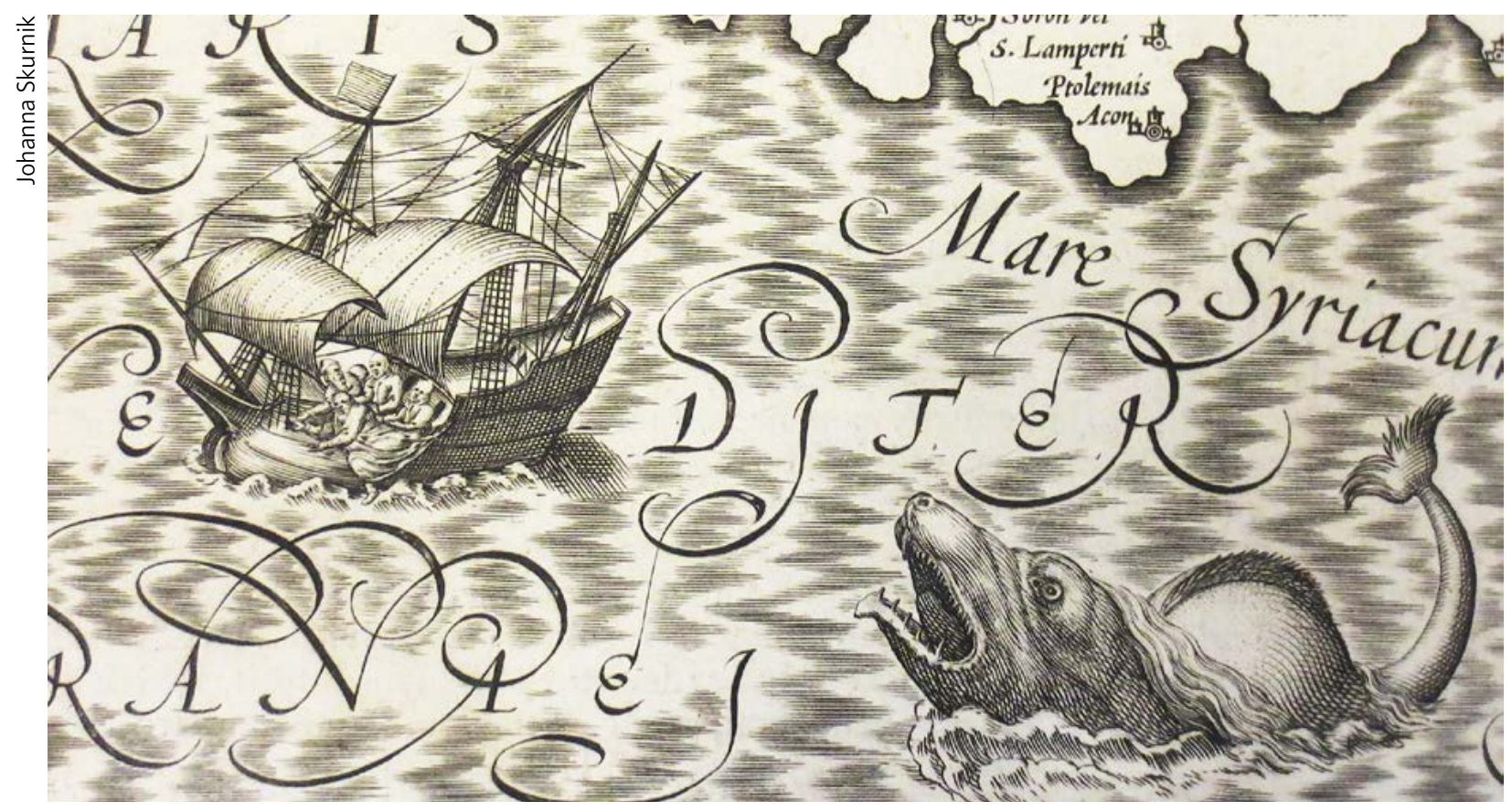

Jonah and Whale depicted in the map of Terra Sancta by Hondius.

maps from a tradition followed by Ortelius in his Theatrum. Although Hondius mostly inserted ethnographical illustrations on land or on the border of the map, the ocean spaces were occasionally utilized for these representations. Therefore, the ways in which the sea was used by humans was an item of information on his maps.

In addition to the abundance of ships on the maps altogether 44 illustrations of sea monsters and other living beings can be found in the atlas. Mercator has produced a quarter of these and three quarters are found on maps by Hondius. This is fewer than the number of illustrations of ships, a fact which can be interpreted to reflect the altered functions of sea monsters in Western cartography from being an indicator of danger to a decorative or informative illustration (van Duzer 2013: 119). ${ }^{27}$ The sea monsters are not depicted as hostile in the atlas, unlike the many illustrated on earlier maps such as Carta Marina (1539) by Olaus Magnus and in treatises such as Cosmographia (1540) by Sebastian Münster (van Duzer 2013: 38-9; Nigg 2013: 30-3, 46-9, 98-103, 112-17, 124-8).

27 As Chet van Duzer (2013: 119) has stated, sea monsters began to disappear from maps in seventeenth century, whilst the ships persisted for longer. It was not till the eighteenth century that a rapid decline in depictions of ships took place.
An exception is a depiction of Jonah and the whale on the map of the Holy Land made by Hondius. This was a very popular theme in Dutch art during this time, from which it was most likely derived (e.g. Unger 1991: 86-9; Sprague 2006: 89-91). The image of Jonah and the whale in this atlas was undoubtedly copied from Ortelius' Theatrum, but it was altered from the original. In Hondius' map the boat is reversed and the sea monster is further away from the ship.

Most of the creatures depicted on the maps by Mercator and Hondius could be classified as generic sea monsters. ${ }^{28}$ Monsters of this kind were circulated amongst map-makers and engravers. ${ }^{29} \mathrm{~A}$ few of these monsters appear on the maps twice, as Hondius uses the same monsters that Mercator had already decorated his maps with in the 1570 s. $^{30}$ Furthermore, most

28 Generic sea monsters are structured as creatures which have fins resembling more a mane than the exact fin of a fish. Their head also resembles more the heads of renowned land animals than marine animals, but the rest of the body seems to accord with those of marine animals such as fishes.

29 The circulation of model books amongst engravers is mentioned by Vyulsteke 1984, cited in van den Broecke 2015: 164 .

30 Many of the sea monsters depicted in maps by Hondius included illustrations that Mercator had already used in his Tabulae geographicae Cl. Ptolemei (1578). Mercator also used these models in maps he added to the atlas (e.g. Mercator 1578; MHA 1613). 

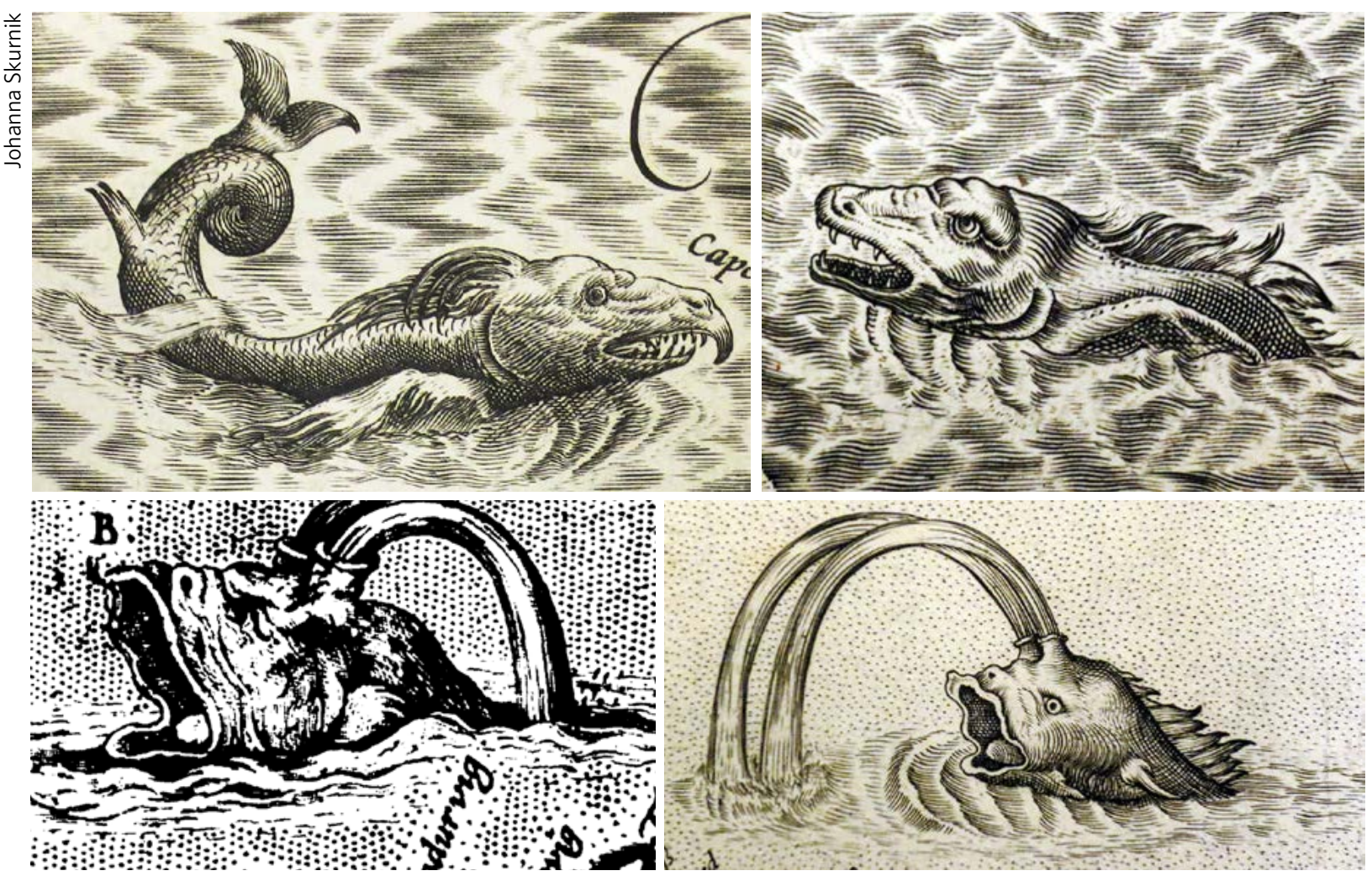

Up on the left a generic sea monster on Hondius' map of Cyprus. It had already been depicted on the map of Taprobana Island in Mercator's Tabulae geographicae Cl. Ptolemei (1578). The generic sea monster on the right is depicted on three maps in the atlas: on the map of the northern part of Ireland by Mercator, as well as the map of Florida and Virginia and Haiti by Hondius. Below on the left is a rorqual whale, depicted on Ortelius's map of Iceland, and on the right the one which is depicted on Mercator's map representing the same island. Ortelius: Islandia [1585], in Ortelius 1601; Mercator: Islandia, MHA 1613.

of the sea monsters on Hondius' maps were exact copies from many other sources, such as Ortelius' atlas and Sebastian Münster's Cosmographie. ${ }^{31}$ Similarly the illustrations of ships were probably copied from other sources. ${ }^{32}$

This kind of copying was typical for many Dutch cartographers, but for Mercator it seems to have been rare. Therefore, it is interesting to see a sea monster depicted on Mercator's map. It may have been copied

31 Additionally, there were copies of monsters depicted in Dutch artwork. For example, the fully open-mouthed fish in the map of Rügen Island in the atlas is a direct copy of similar fish in Three Caravels in a Rising Squall with Arion on a Dolphin from The Sailing Vessels by Pieter Bruegel the Elder (1525-69) (Orenstein 2001; The Metropolitan Museum of Art 2015).

32 Many of the ships depicted in the atlas seem to be similar to ones made by earlier cartographers, but they were also replicated from works produced by Dutch artists (see, e.g., Russell 1983: 51-61). from Ortelius. On Mercator's map of Iceland there is an illustration of a rorqual whale, which is very similar to the one on Ortelius' map of Iceland. ${ }^{33}$ If it is a copy, the reason for reproducing it is difficult to ascertain. Perhaps it was copied because it was one of the only sea creatures on Ortelius' map that represented existing marine animals. Other creatures on Ortelius' map of Iceland were mostly based in mythical creatures such as the kraken (Nigg 2013: 16-17).

The rorqual whale is a good example of a depiction of an existing marine animal, which follows the illustrations used by Olaus Magnus and Sebastian Münster. Several maps by Hondius include fishes

33 The precise date when Mercator made his map is not known, but it was not published until 1595, within the Mercator Atlas, whereas the map of Islandia by Ortelius includes in the description an indication that it had already been displayed in 1585 . Ortelius: Islandia, in Ortelius 1601; Mercator: Islandia, MHA 1613 . 

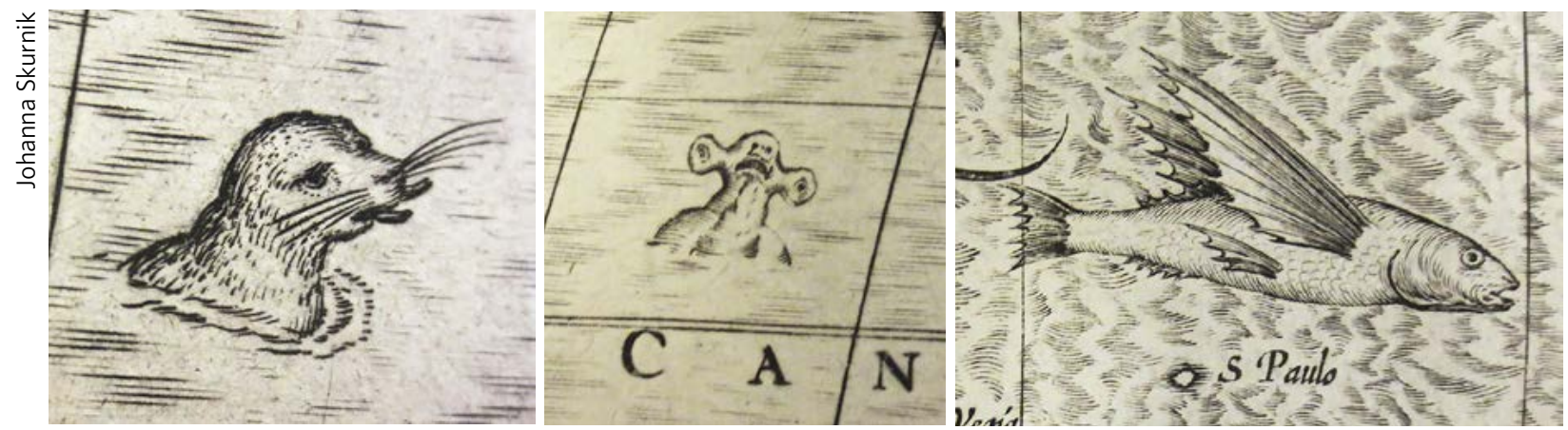

Three marine animals depicted in very a realistic manner on maps by Hondius.

peeking above the surface of the water. These were undoubtedly replicated from Münster's Cosmography (1553: i, iii). In addition, there are few marine animals on Hondius' maps, and they are depicted in a more realistic manner than others. They include the head of a seal near the polar region on the map of Europe; the head of a hammerhead shark in the northern Pacific on the map of America and several flying fish in sea areas near America. ${ }^{34}$ These illustrations can, therefore, be seen as examples of emerging new ideals in natural history which emphasize the production of the most empirical and objective illustrations of the subject as possible (see, e.g., Glardon 2011: 125-6).

Furthermore, following Wilma George (1969), marine animals can be interpreted as being characteristic of certain sea areas in the same fashion as some depictions of animals on land. These include, for example, the seal in the Arctic Ocean and flying fishes in tropical waters. For the map-makers' contemporaries these marine animals, however, were examples of exotic marine life. As the historian Jonathan Sell (2006: 75) states, flying fishes were occasionally dealt with in the same context as mermen. Consequently, these illustrations were not mere decorations; rather they functioned as examples of knowledge concerning the vitality of the oceans.

Although Hondius himself viewed the illustrations included on the ocean spaces mainly as a means of making a profit, the significance of the marine depictions on his maps was different for the readers. They exemplified the skills of engravers and rendered the ocean space highly decorative and enjoyable to

34 See, e.g., Hondius: Europea; Hondius: America; Hondius: Hispaniola Insula; Hondius: America Meridionalis; MHA 1613. look at. In addition, the depictions applied to the marine areas in Hondius' maps offered both ethnographical and natural historical information to the readers of the atlas.

The maps prepared by Mercator stand out in stark contrast by comparison with the abundantly illustrated oceans of Hondius' ethnographical and natural historical maps. Mercator's reasons for only adding a few illustrations to his maps are open to various interpretations. Chet van Duzer (2013: 105-6) proposes that as Mercator grew older, he was possibly less interested in decorations. Or, perhaps he simply enjoyed being a cartographer who sold maps without the added extra of illustrations. Perhaps the far distance of his hometown, Duisburg, from the centres of cartography affected his map-making methods, as the geographer Nicholas Crane (2003: 252-3) speculates in his biography of Mercator.

Ultimately, no definitive explanation exists for Mercator's humble style. The exiguous opulence of the ocean spaces appears to be even more extraordinary if one takes into consideration the fact that Mercator illustrated his famous 1541 terrestrial globe with several sea monsters (van Duzer 2013: 86-8; Harvard College Library 2015). ${ }^{35}$ The richness of the sea monster and ship illustrations was present also in his 1569 world map (van Duzer 2013: 103-5). ${ }^{36}$ After these works, Mercator began to reduce the

35 The model of these sea monsters derived from the Olaus Magnus' Carta Marina (1539) and from Gonzalo Fernández de Oviedo y Valdés' Historia general de las Indias (1535).

36 In his 1569 world map, Mercator used a whole different source. He abandoned the monsters by Olaus Magnus and used as his source almost solely $D e$ aquatilibus libri duo (1553) by the renowned natural historian and ichthyologist Pierre Belon. 
number of illustrations on the sea areas. In addition, he changed his style, no longer using copied illustrations, but adding generic sea monsters which he possibly designed himself.

The different approaches to illustrating the ocean spaces on the maps of Hondius and Mercator are clear. However, they both transmitted different kinds of ideas about the ocean geographies. In this regard, the Mercator-Hondius Atlas offered its readers more diverse viewpoints regarding ocean spaces. Compared to the earlier tradition of depicting ocean spaces as dangerous - with, for example, illustrations of monsters eating humans - the atlas maps depicted them differently. The maps communicated information to the reader about the varieties of cultures, the different ships and both marvellous and more commonplace sea animals. In addition, the maps provided enjoyable depictions of various sea monsters and ships.

\section{Conclusions}

The illustrations and textual descriptions on the maps, authored by different individuals and bound together in this edition of the Mercator-Hondius Atlas, demonstrate clearly the epistemologically layered nature of the atlas as an artefact. The information that was passed on by the atlas maps was derived from different kinds of sources. Cartographers relied increasingly on information from travellers, but also drew conclusions based on the classical authorities, biblical sources and hearsay. The methods used to construct knowledge varied, as did the motives for making particular choices concerning the maps.

The atlas maps make explicit the different epistemological choices made and the ontological categories used - how the world was made known and what was represented as known. The observations made by travellers and the theories entertained are transformed into images of the world as places and things are situated on the maps. The continental geographies are abundant with illustrations and descriptions of ethnographical information and the characteristics of the environment and the resources observed, speculated upon, or hoped for. What remained unknown was either filled with speculations or left completely empty.

Just like the unknown peripheries, oceans are practically devoid of information. The emptiness of the oceans highlights the terracentric nature of atlases. However, as our analysis demonstrates, analys- ing how the oceans are illustrated is of significance. On the one hand, the various ships sailing along the trade routes demonstrate the function of the ocean as a passage. On the other hand, sea monsters are used to decorate that which is unknown - as generic images of the unexplored and as intriguing details for the reader to examine. However, the earlier function of the sea monsters as an indication of danger is no longer evident. Furthermore, the few realistic depictions of marine animals can be seen as a sign that the illustrations, perhaps, passed on information based on observations as well. The sea monsters and the marine animals on the maps, therefore, are indications of the knowledge and insights attached to the ocean spaces.

As our examination excluded the on verso texts of the atlas, the conclusions that can be drawn about the atlas as an artefact transmitting knowledge of the world are, of course, limited. However, our analysis of the illustrations and textual descriptions used in the maps has resulted in a comparative description of the different means and types of knowledge communicated through the maps.

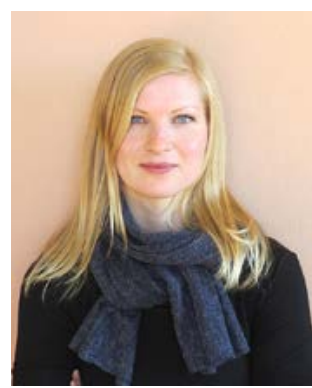
MA Johanna Skurnik is a PhD candidate in European and World History at the University of Turku. Her research interests are history of knowledge, history of cartog- raphy and historical geography. In her thesis Skurnik examines British geographies of colonial Australia in the mid-nineteenth century.

MA Otto Latva is a PhD candidate in Cultural History at the University of Turku. In his thesis Latva studies perceptions and attitudes towards the deep sea dwelling squid, the giant squid, in western culture from the late eighteenth century to the turn of the twentieth century. His research interests includes history of animals, history of natural sciences and the oceanic research from the perspective of cultural history. 


\section{Bibliography}

Primary sources

Mercator, Gerard, 1578. Tabulae geographicae Cl. Ptolemei (typis Godefridi Kempensis)

-1585a. Belgii inferioris geographicae tabule (Duysburgi)

-1585b. Galliae tabule geographicae (Duysburgi Cliorum)

-1585c. Germaniae tabule geographicae (Duysburgi)

-1595. Atlas sive cosmographicae meditationes de fabrica mundi et fabricati figura. (Geographia nova totius mundi) (Albertus Busius)

MHA = Mercator, Gerard, and Jodocus Hondius, 1613 . Atlas sive cosmographicae meditationes de fabrica mundi et fabricati figura, editio quarta (Amsterodam, Iudoci Hondij)

Münster, Sebastian, 1553. Cosmographei oder beschreibung aller länder, herrschafften, fürnemsten stetten, geschichte[n], gebreüchen, hantierungen etc. (Basel, Heinrich Petri)

Ortelius, Abraham, 1572. Theatre de l'vnivers, contenant les cartes de tout le monde, avec vne brieve declaration d'icelles...

-1601. Theatrum orbis terrarum Abrahami Ortelii. Quod ante extremum vitae suae diem, postremum recensuit, nouis Tabulis et Commentarijs auxit atque illustrauit (Antverpiae, ex officina Plantiniana, apud Ioannem Moretum)

\section{Secondary sources}

Brotton, Jerry, 2012. A History of the World in Twelve Maps (London, Penguin Books Ltd)

Cosgrove, Denis, 2007. 'Mapping the world' in Maps: Finding our Place in the World, eds. James R. Akerman and Robert W. Karrow Jr (The University of Chicago Press), pp. 65-115

Crane, Nicholas, 2003. Mercator: The Man Who Mapped the Planet (London, Phoenix)

Crone, Gerald Roe, 1978. Maps and their Makers: An Introduction to the History of Cartography, 5 th edn (Dawson, Archon Book)

Daston, Lorraine, and Katharine Park, 1998. Wonders and the Order of Nature 1150-1750 (New York, Zone Books)

Delano-Smith, Catherine, 2007. 'Signs on printed topographical maps, ca.1470-ca.1640' in History of Cartography, vol. 3, Cartography in the European Renaissance, part 1, ed. David Woodward (University of Chicago Press), pp. 528-9o

della Dora, Veronica, 2009. 'Performative atlases: memory, materiality, and (co-)authorship', Cartographica, 44(4), pp. 240-55

Gascoigne, John, 2014. Encountering the Pacific in the Age of the Enlightenment (New York, Cambridge University Press)

George, Wilma, 1969. Animals and Maps (London, Secker and Warburg)

Glardon, Philippe, 2011. 'The relationship between text and illustration in mid-sixteenth-century natural history treatises' in A Cultural History of Animals in the Renaissance, ed. Bruce Boehrer (Oxford and New York, Berg), pp. 119-45

Harvard College Library, 2015. 'An introduction to The Mercator Globes at Harvard Map Collection', <http:// hcl.harvard.edu/libraries/maps/exhibits/mercator/ main.html> (accessed 2.9.2015)

Holzer, Gerhard, Valerie Newby, and Petra Svatek, 2015. A World of Innovation: Cartography in the Time of Gerhard Mercator (Cambridge Scholars Publishing)

Karrow, Robert W. Jr, 2007. 'Introduction' in Maps: Finding our place in the World, eds. James R. Akerman and Robert W. Karrow Jr (The University of Chicago Press), pp. 1-17

Keuning, Johannes, 1947. 'The history of an atlas: Mercator. Hondius', Imago Mundi, 4, pp. 37-62

Koeman, Cornelis, 1965. 'Jodocus Hondius' wall-map of Europe, 1595', Imago Mundi, 19, pp. 108-10

Koeman, Cornelis, Günter Schilder, Marco van Egmond, and Peter van der Krogt, 2007. 'Commercial cartography and map production in the Low Countries, 1500 - ca. 1672' in History of Cartography, vol. 3, Cartography in the European Renaissance, part 1, ed. David Woodward (University of Chicago Press), pp. 1296-1383

Lewis, Martin L., and Kären Wigen, 1997. The Myth of the Continents: A Critique of Metageography (Berkeley, University of California Press)

Lindgren, Uta, 2007. 'Land surveys, instruments, and practitioners in the renaissance' in History of Cartography, vol. 3, Cartography in the European Renaissance, part 1, ed. David Woodward (University of Chicago Press), pp. 477-508

The Metropolitan Museum of Art, 2015. 'Three Caravels in a Rising Squall with Arion on a Dolphin from The Sailing Vessels', <http://www.metmuseum.org/collection/the-collection-online/search/338713?rpp=30\&pg $=3 \& \mathrm{ft}=$ Pieter + Bruegel $\&$ pos $=61>($ accessed 2.10 .2015$)$

Meurer, Peter H., 1998. 'De verkoop van de koperplaten van Mercator naar Amsterdam in 1604, CaertThresoor, 17(3), pp. 61-8

Nigg, Joseph, 2013. Sea Monsters: The Lore and Legacy of Olaus Magnus's Marine Map (East Sussex, Ivy Press)

Okhuizen, Edwin, 1994. 'De kaart van de Noordpol in Mercator's Atlas of 1595, Caert-Thresoor, 13(1), pp. 5-10

Orenstein, Nadine (ed.), 2001. Pieter Bruegel the Elder: Drawings and Prints (New York, Metropolitan Museum of Art)

Pelletier, Monique, 2009. De Ptolémée à La Guillotière (XVe-XVIe siècle). Des cartes pour la France pourquoi, comment? (Paris, Comité des travaux historiques et scientifiques -CTHS)

RKD Netherlands Institute for Art History, 2015. 'Baptista van Doetecum', <https://rkd.nl/explore/artists/429818> (accessed 6.10.2015)

Russell, Margarita, 1983. Visions of the Sea: Hendrick C. Vroom and the Origins of Dutch Marine Painting (Leiden, Brill Archive) 
Schilder, Günter, 1984. 'Development and achievements of Dutch northern and arctic cartography in the sixteenth and seventeenth centuries', Arctic, 37(4), pp. 493-514

Schilder, Günter, and Marco van Egmond, 2007. 'Maritime cartography in the Low Countries during the renaissance' in History of Cartography, vol. 3, Cartography in the European Renaissance, part 1, ed. David Woodward (University of Chicago Press), pp. 1384-1432

Schmidt-Biggemann, Wilhelm, 1987. 'Lubinus, Eilhard' in Neue Deutsche Biographie, 15, pp. 263 f., <http:// www.deutsche-biographie.de/pnd100974325.html> (accessed 6.10.2015)

Sell, Jonathan P. A., 2006. Rhetoric and Wonder in English Travel Writing, 1560-1613 (Aldershot and Burlington, Ashgate)

Smith, Bernard, 1992. Imagining the Pacific: In the Wake of the Cook Voyages (New Haven and London, Yale University Press)

Snyder, John, 2007. 'Map projections in the Renaissance' in History of Cartography, vol. 3, Cartography in the European Renaissance, part 1, ed. David Woodward (University of Chicago Press), pp. 365-81

Sprague, Tiffany, 2006. 'Maarten de Vos. Antwerp 15321603 Antwerp. Jonah Thrown Overboard. 1580s' in Master Drawings from the Yale University Art Gallery (New Haven, Yale University Press), pp. 89-91

Steinberg, Philip E., 2001. The Social Construction of the Ocean (Cambridge University Press)

Suarez, Thomas, 1999. Early Mapping of Southeast Asia: The Epic Story of Seafarers, Adventurers, and Cartographers Who First Mapped the Regions Between China and India (Singapore, Periplus)

Sutton, Elizabeth A., 2009. 'Mapping meaning: ethnography and allegory in Netherlandish cartography, 1570-1655', Itinerario 33(3), pp. 13-42

-2012. Early Modern Dutch Prints of Africa (Farnham and Burlington, Ashgate)

Tooley, Ronald Vere, 1949. Maps and Map-Makers (London, Batsford)

Unger, Richard W., 1991. 'Marine paintings and the history of shipbuilding' in Art in History/History in Art: Studies in Seventeenth-Century Dutch Culture, eds. David Freedberg and Jan de Vries (Santa Monica, Getty Publications), pp. 75-94

-2010. Ships on Maps: Pictures of Power in Renaissance Europe (New York, Palgrave Macmillan)

Van den Broecke, Marcel, 1996. Ortelius Atlas Maps: An Illustrated Guide (Houten, HES Publishers)

-2009. Ortelius' Theatrum Orbis Terrarum (1570-1641): Characteristics and Development of a Sample of On Verso Map Texts (Utrecht, Koninklijk Nederlands Aardrijkskundig Genootschap Faculteit Geowetenschappen Universitet Utrecht)

-2015. 'Mercator and Ortelius - two of a kind?' in A World of Innovation: Cartography in the Time of Gerhard Mercator; eds. Gerhard Holzer, Valerie
Newby, and Petra Svatek (Cambridge Scholars Publishing), pp. 112-30

Van der Krogt, Peter, 1996. 'Amsterdam atlas production in the 1630s: a bibliographer's nightmare', Imago Mundi, 48, pp. 149-60

-1997. Koeman's Atlantes Neerlandici, new edition, vol. 1, The Folio Atlases published by Gerard Mercator, Jodocus Hondius, Henricus Hondius, Johannes Janssonius and their successors ('t Goy-Houten, HES Publishers)

-2005. Joan Blaeu, Atlas Maior of 1665, introduction and texts by Peter van der Krogt, directed and produced by Benedikt Taschen (Köln etc., Taschen Verlag)

-2015. 'Gerhard Mercator and his cosmography: how the "Atlas" became an atlas' in A World of Innovation: Cartography in the Time of Gerhard Mercator, eds. Gerhard Holzer, Valerie Newby, and Petra Svatek (Cambridge Scholars Publishing), pp. 112-30

Van Duzer, Chet, 2012. 'Hic sunt dracones: the geography and cartography of monsters' in The Ashgate Research Companion to Monsters and the Monstrous, ed. Asa Simon Mittman (Farnham and Burlington, Ashgate), pp. $387-435$

-2013. Sea Monsters on Medieval and Renaissance Maps (London, British Library)

Wallis, Helen, 1984. 'The cartography of Drake's voyage' in Sir Francis Drake and the Famous Voyage, 15771580: Essays Commemorating the Quadricentennial of Drake's Circumnavigation of the Earth, ed. Norman Joseph William Thrower (Los Angeles, University of California Press), pp. 121-63

Woodward, David, 2007. 'Cartography and the Renaissance: continuity and change' in History of Cartography, vol. 3, Cartography in the European Renaissance, part 1, ed. David Woodward (University of Chicago Press), pp. 365-81

Zuber, Mike A., 2011. 'The armchair discovery of the unknown southern continent: Gerardus Mercator, philosophical pretensions and a competitive trade, Early Science and Medicine, 16, pp. 505-41 